\title{
Herbal Extract SH003 Suppresses Tumor Growth and Metastasis of MDA-MB-231 Breast Cancer Cells by Inhibiting STAT3-IL-6 Signaling
}

\author{
Youn Kyung Choi, ${ }^{1}$ Sung-Gook Cho, ${ }^{1}$ Sang-Mi Woo, ${ }^{1}$ Yee Jin Yun, ${ }^{1}$ Sunju Park, ${ }^{2}$ \\ Yong Cheol Shin, ${ }^{1}$ and Seong-Gyu Ko ${ }^{1}$ \\ ${ }^{1}$ Lab of Clinical Biology and Pharmacogenomics, Department of Preventive Medicine, College of Korean Medicine, \\ Kyung Hee University, Seoul 130-701, Republic of Korea \\ ${ }^{2}$ Department of Preventive Medicine, College of Korean Medicine, Daejeon University, 62 Daehak-ro, Dong-gu, \\ Daejeon 300-716, Republic of Korea
}

Correspondence should be addressed to Seong-Gyu Ko; epiko@khu.ac.kr

Received 17 February 2014; Revised 8 May 2014; Accepted 9 May 2014; Published 25 May 2014

Academic Editor: Chang Shik Yin

Copyright (C) 2014 Youn Kyung Choi et al. This is an open access article distributed under the Creative Commons Attribution License, which permits unrestricted use, distribution, and reproduction in any medium, provided the original work is properly cited.

Cancer inflammation promotes cancer progression, resulting in a high risk of cancer. Here, we demonstrate that our new herbal extract, SH003, suppresses both tumor growth and metastasis of MDA-MB-231 breast cancer cells via inhibiting STAT3-IL-6 signaling path. Our new herbal formula, SH003, mixed extract from Astragalus membranaceus, Angelica gigas, and Trichosanthes kirilowii Maximowicz, suppressed MDA-MB-231 tumor growth and lung metastasis in vivo and reduced the viability and metastatic abilities of MDA-MB-231 cells in vitro. Furthermore, SH003 inhibited STAT3 activation, which resulted in a reduction of IL-6 production. Therefore, we conclude that SH003 suppresses highly metastatic breast cancer growth and metastasis by inhibiting STAT3-IL-6 signaling path.

\section{Introduction}

Triple-negative breast cancer (TNBC) constituting 10-20\% in breast cancer is highly metastasizing and recurrent with poorer prognoses [1-3]. Although TNBC is sensitive to chemotherapies, TNBC metastases frequently occur and shorten 5-year survival rates of patients [1,3]. Furthermore, target therapies for TNBC remain yet to be clearly elucidated in clinical trials. Recent studies in cancer therapeutics revisit a traditional herbal medicine, since herbal extracts or mixtures based on the traditional medicines have shown anticancer effects with no or less side effects compared to other anticancer therapeutics including chemical compounds and targeting antibodies [4-6]. Anticancer effects of herbal extracts from Astragalus membranaceus (Am), Angelica gigas (Ag), or Trichosanthes Kirilowii Maximowicz (Tk) have been revealed in different cancer cell types such as leukemia, hepat- ocellular carcinoma, colon cancer, non-small-cell lung cancer, and gastric cancer cells [7-13]. Furthermore, extracts from a mixture of $\mathrm{Am}$ and $\mathrm{Ag}$ have been shown to affect various diseases including hematologic diseases or endocrine disorders [14-16].

Inflammation is a risk factor in cancer disease [1722], which is tightly linked to cancer progression including tumorigenesis and metastasis $[23,24]$. Cancer inflammation is activated by several inflammatory cytokines such as TNF$\alpha$, IL-1, IL-6, IL-8, and IL-18 [25]. Particularly, IL-6 as a poor prognostic factor in breast cancer patients progresses cancer metastasis [26]. In addition, IL-6-induced dimerization of IL-6 receptor activates STAT3, which contributes to cancer progression in cancer inflammatory environment $[27,28]$. Recent studies have shown that STAT3 activation leads to TNBC progression, suggesting that STAT3 is likely to be a therapeutic target for TNBC $[29,30]$. 
On the basis of the traditional medicine, SH003 was extracted from the herbal mixtures of $\mathrm{Am}, \mathrm{Ag}$, and $\mathrm{Tk}$. SH003 showed anticancer effects on different breast cancer cells without affecting normal epithelial cell viability, both in vitro and in vivo. Moreover, $\mathrm{SH} 003$ suppresses MDA-MB231 growth and metastasis by inhibiting STAT3-IL-6 pathway, thereby suggesting that $\mathrm{SH} 003$ may be useful for treating TNBC.

\section{Materials and Methods}

2.1. Reagents, Preparation of SH003, and Cell Lines. SH003 consists of Am, Ag, and Tk, which is based on the principle of the traditional medicine. All extracts were provided from Hanpoong Pharm and Foods Company (Jeonju, Republic of Korea) manufactured by the Good Manufacturing Product (GMP). Dried extracts were dissolved in 30\% ethanol to prepare a stock solution of $20 \mathrm{mg} / \mathrm{mL}$. The stock solution was stored at $-80^{\circ} \mathrm{C}$. HPLC and UPLC were performed to confirm characteristics of herbal mixtures including each component (Hanpoong Pharm and Foods Company). Breast cancer cell lines, MCF-7 (hormone-positive), T47D (hormone-positive), SKBR-3 (HER-2-positive), BT-20 (TNBC, noninvasive), and MDA-MB-231 (TNBC, highly metastatic) were cultured in DMEM medium with $10 \%$ fetal bovine serum and $1 \%$ antibiotics. Rat normal intestinal epithelial cells (RIEs) were also cultured in the same condition as above. GBL-60 cells (kindly provided by Dr. Sun Ha Paek at Seoul National University Hospital, Seoul, Republic of Korea) isolated from the brain of a patient who suffered from brain-metastasized breast cancer were also cultured in DMEM, which was approved by an Institutional Review Board at the Seoul National University Hospital [31].

2.2. Cell Viability Assay and Flow Cytometry. Cells were seeded on 96-well plates and treated with different herbal extracts for 24 hours to 72 hours. Cell viability was measured by MTT assays. Absorbance was read at $570 \mathrm{~nm}$ on the ELISA reader (Molecular Devices, Palo Alto, CA, USA). Cells were seeded in 6-well plates and treated with each extract for 24 hours. Cells were then harvested and stained with propidium iodide (PI, $50 \mu \mathrm{g} / \mathrm{mL}$ ) at room temperature in the dark. PI-positive cells were detected using FACSCalibur (BD Biosciences, San Jose, CA, USA).

2.3. Cell Migration, Invasion Assay, and Anchorage-Independent Assay. Cell migration was measured by scratching assays. Cells were seeded in 6-well plates and then scratched. 24 hours after treatments with herbal extracts, migrated cell numbers were counted. For invasion assays, cells were cultured in the upper chambers precoated with matrigels and treated with each extract for 24 hours. After swapping the upper chamber carefully, invaded cell numbers in four fields randomly chosen were counted. For anchorage-independent assays, cells were cultured on soft agar plates and treated with extracts every second day. At day 15 , cells were stained with $0.5 \%$ crystal violet to be visualized and colonies were counted with photomicroscope.
2.4. Western Blot and Immunofluorescence Assays. Cells were lyzed with RIPA buffer and total $30 \mu \mathrm{g}$ of protein was loaded on 6-12\% SDS-PAGE. After transferring to PVDF membranes, each membrane was blotted with the appropriate antibodies. Anti-PARP, -p-EGFR, -EGFR, -p-STAT3, -STAT3, -p-JAK1, -p-JAK2, -p-AKT, and -AKT antibodies were purchased from Cell Signaling (Danvers, MA, USA). Anti-p-SRC, -SRC, -p-ERK1/2, -ERK1/2, -VEGF, -Cyclin D, MMP-9, -Survivin, and -Tubulin were purchased from Santa Cruz Biotechnology (Santa Cruz, CA, USA). Immunofluorescence assays for p-STAT3 nuclear translocation in MDAMB-231 cells were done with anti-p-STAT3 antibody and antiAlexa Fluor-488 antibody (Invitrogen, Eugene, OR, USA). For the counter staining, TOPRO-3 (Invitrogen, Eugene, OR, USA) was used to stain the nucleus. Images were obtained with Olympus FV10i Self-Contained Confocal Laser System.

2.5. Luciferase Assay. Luciferase assays were performed with the dual luciferase assay kits (Promega, Madison, WI, USA) according to the manufacturer's instructions. In brief, p4xM67-TK-luc plasmid (Addgene plasmid 8688, Addgene, Cambridge, MA, USA) [32] containing four copies of the STAT-binding site (TTCCCGTAA) was transfected in 293T or MDA-MB-231 cells and then extracts were treated for 24 hours. EF.STAT3C.UBC.GFP and EF.STAT3DN.UBC.GFP (Addgene plasmids 24983 and 24984, Addgene, Cambridge, MA, USA) [33] were transfected into 293T or MDA-MB231 cells, which were subjected to the luciferase assays. Luciferase assays were conducted in quadruplicate and independently repeated at least three times. Representative data were described as means \pm standard deviations. For knockdown strategies, pSIH1-puro-STAT3 shRNA (Addgene plasmid 26596, Addgene, Cambridge, MA, USA) [34] was used.

2.6. Real-Time PCR, Chromatin Immunoprecipitation Assays, and ELISA. Total RNAs were extracted with Trizol (Invitrogen, NY, USA). After measuring the RNA concentration by using the NanoDrop ND-1000 spectrophotometer, $1 \mu \mathrm{g}$ of total RNA was reverse-transcribed using cDNA synthesis kit (TaKaRa, Kusatsu, Shiga, Japan). GAPDH was used for an internal control. Primers used are as follows: $5^{\prime}$-AATCCCATCACCATCTTCCA-3' (GAPDH F), 5' -TGGACTCCACGACGTACTCA-3' (GAPDH R), 5'-AACCTTCCAAAGATGGCTGAA- $3^{\prime}$ (IL-6 F), and $5^{\prime}$-CAGGAACTGGATCAGGACTTT-3' (IL-6 R). Quantitative real-time PCRs were performed using SYBR green Master Mix (Takara, Shiga, Japan) in LightCycler 480 (Roche, Switzerland). Chromatin immunoprecipitation (ChIP) assays were performed using EpiSeeker ChIP kit (Abcam, Cambridge, UK) according to the manufacturer's instructions. In brief, cells were treated with $\mathrm{SH} 003$ for 3 hours and then fixed with $0.75 \%$ formaldehyde. Lysates were then sonicated and immunoprecipitated with anti-STAT3 antibody (Cell Signaling, Danvers, MA, USA). After reverse crosslinking, immunoprecipitated and purified DNA fragments were subjected to real-time PCRs. STAT3 binding region ( $-143 \mathrm{bp} \sim 48 \mathrm{bp}$ ) was amplified using primers as follows: F: 


\begin{tabular}{cc}
\hline Herbal composition & Amount used $(\mathrm{g})$ \\
\hline $\begin{array}{c}\text { Astragalus } \\
\text { membranaceus } \\
\text { Angelica gigas } \\
\text { Trichosanthes } \\
\text { Kirilowii Maximowicz }\end{array}$ & 333 \\
\hline Total amounts & 333 \\
\hline
\end{tabular}

(a)
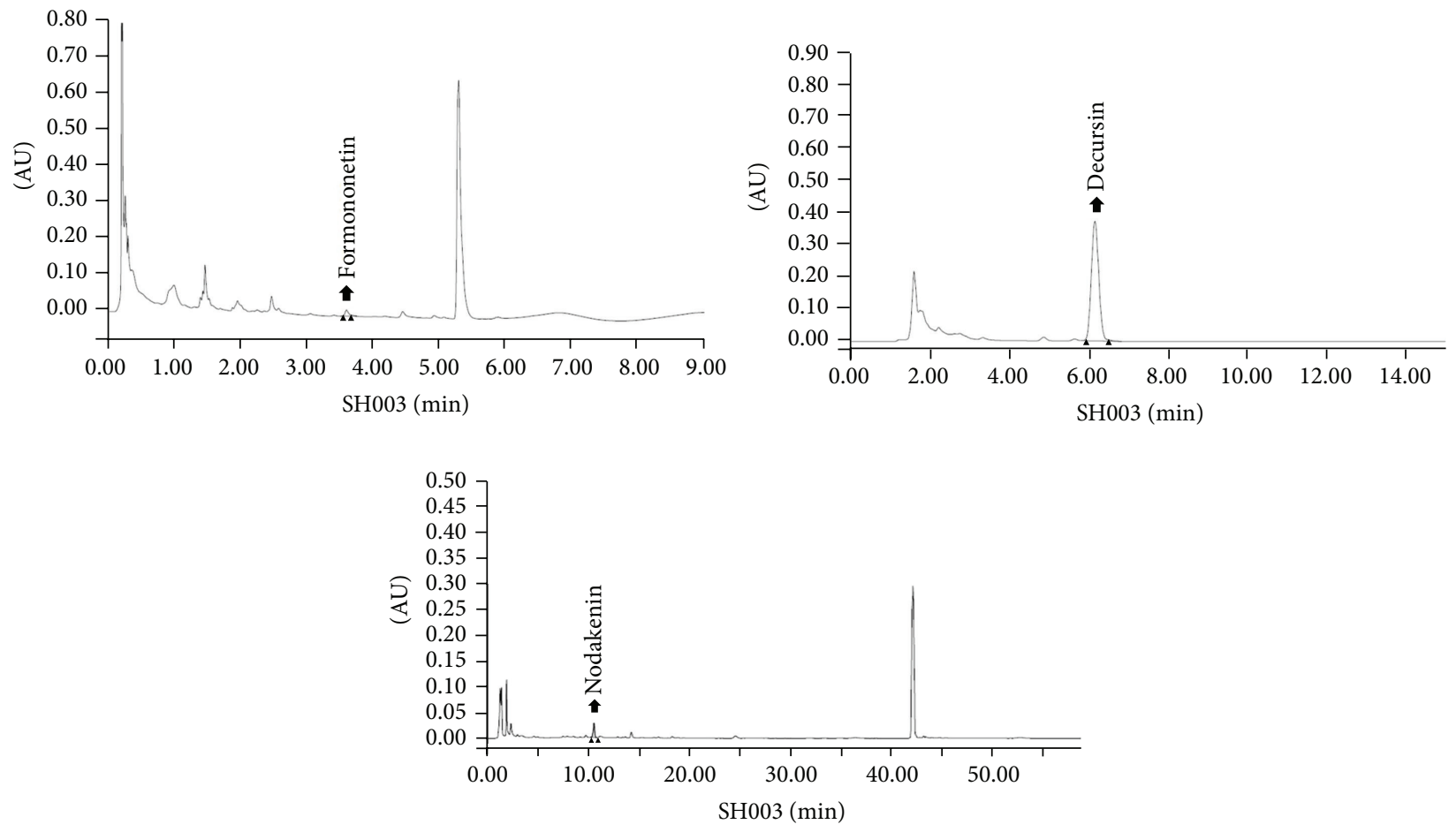

(b)

FIGURE 1: HPLC profile of SH003. (a) Composition of SH003. (b) HPLC identification of components in SH003. Formononetin, decursin, and nodakenin were detected in Am and Ag. Three components in SH003 were detected at $3.6 \mathrm{~min}, 6.1 \mathrm{~min}$, and $11.0 \mathrm{~min}$.

5'-GTTGTGTCTTGCCATGCTAAAG-3', R: 5'-AGAATGAGCCTCAGACATCTCC- ${ }^{\prime}$. ELISAs were performed with human IL-6 ELISA kit (BD Biosciences,San Jose CA, USA) according to the manufacturer's instructions.

2.7. In Vivo Studies. Animal studies were approved by Kyung Hee University Institutional Animal Care and Use Committee (KHU-IACUC). Six-week-old nude $(\mathrm{Nu} / \mathrm{Nu})$ mice were purchased from Oriental Science and injected s.c. with $1 \times 10^{6}$ MDA-MB-231 cells. When tumor volume reached $50 \mathrm{~mm}^{3}$, mice were randomly grouped and extracts were p.o. added daily. Body weights and tumor volumes were measured three times a week. At the end of experiments, mice were sacrificed and all organs including tumors were fixed with $4 \%$ formaldehyde. Blood was also taken from the heart and subjected to the blood test. Lung metastasis was measured by counting metastatic colony numbers on lungs. Fixed organs were embedded in paraffin and stained with hematoxylin and eosin for histological observations. Immunohistochemistry was performed with anti-CD31 antibody (Abcam, Cambridge, UK).

2.8. Statistics. Data were presented as means and standard deviations. $P$ values less than 0.05 in the two-tailed Student's $t$-test were considered statistically significant.

\section{Results}

3.1. HPLC Analysis of SH003. SHOO3 was extracted from the mixture of three different herbs (Figure 1(a)). A characterization of $\mathrm{SH} 003$ was based on retention times and UV spectra of standard chemicals at wavelengths of $260 \mathrm{~nm}$ (formononetin), $280 \mathrm{~nm}$ (decursin), and $330 \mathrm{~nm}$ (nodakenin): formononetin (3.6 min) for Am, decursin (6.1 min) for Ag, and nodakenin (11.0 min) for Ag (Figure 1(b)). However, we 


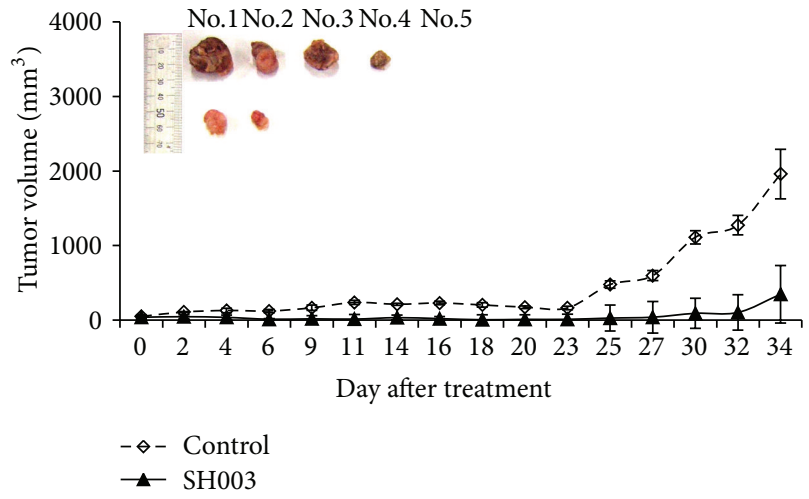

(a)
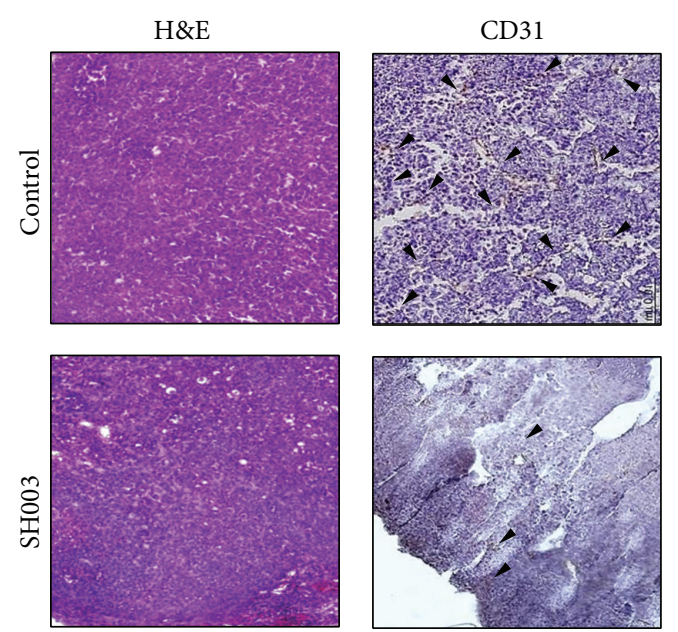

(c)

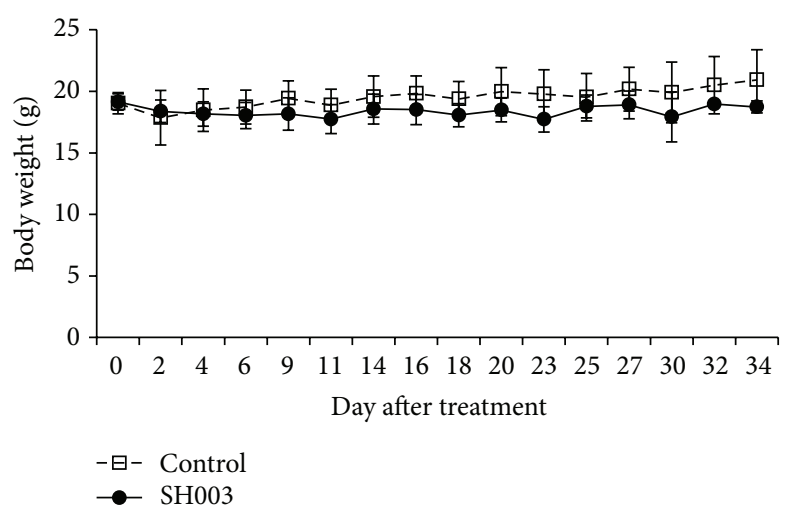

(b)

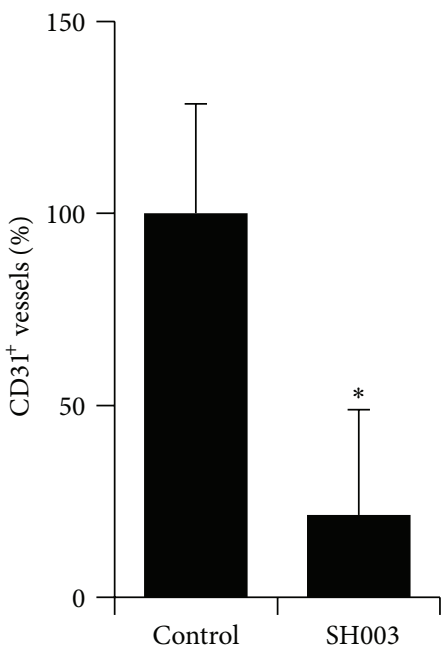

(d)

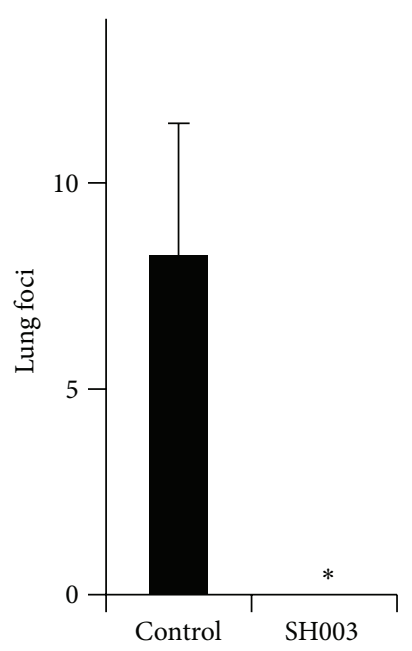

(e)

FiguRE 2: SH003 suppresses tumor growth in vivo. (a) $1 \times 10^{6}$ MDA-MB-231 cells were s.c. injected and nude mice ( $n=5 /$ group) were p.o. administrated with the indicatives until 34 days. Xenograft tumor volumes were measured three times a week by a caliper. ${ }^{*} P<0.05$. (b) Body weights were measured three times a week. (c) Tumor tissues were stained with hematoxylin and eosin. Photo images were taken at 20x magnification. Tumor tissues were also stained with anti-CD31 antibody to detect tumor angiogenic vessels. The bar indicates $10 \mu \mathrm{m}$. (d) To measure tumor angiogenic vessels in tumor cohorts, CD31-positive vessels were counted. ${ }^{*} P<0.05$. (e) Pulmonary metastases were determined by counting foci at lungs.

failed to detect an index compound for Tk. We assumed that technical limitations might cause that failure.

\subsection{SH003 Inhibits MDA-MB-231 Tumor Growth and Metas-} tasis In Vivo. To examine anticancer effects of $\mathrm{SH} 003$ on MDA-MB-231 cells in vivo, we performed the xenograft mouse tumor growth assays. When mice were orally administrated with SH003 (500 mg/kg) every day and sacrificed at day 34 posttreatment, extracts repressed tumor growth. Average tumor volumes of control $(n=4)$ and SH003 $(n=5)$ at day 34 were approximately $1958.74 \mathrm{~mm}^{3}$ and $348.164 \mathrm{~mm}^{3}$, respectively (Figure 2(a)). In addition, $\mathrm{SH} 003$ did not affect body weights of mice until 34 days (Figure 2(b)).

When tumor tissues were stained with hematoxylin and eosin, we found that tumor cohort treated with SH003, compared to that with control, was well differentiated (Figure 2(c)). Tumor tissues were then stained with antiCD31 antibodies to detect tumor vessels because tumor angiogenesis is a bridge for distant metastasis [35]. SH003 compared to the control reduced vessel numbers in tumor burdens by approximately $79 \%$ (Figures 2(c) and 2(d)). Thus, our data indicate that $\mathrm{SH} 003$ inhibits tumor growth.

Next, we conducted in vivo experimental metastasis assays to examine $\mathrm{SH} 003$ effect on a distant metastasis. When metastatic tumor colonies on lungs were counted, SH003 compared to control strongly reduced colony numbers by approximately $100 \%$ (Figure $2(\mathrm{e})$ ). Thus, our data indicate that SH003 inhibits MDA-MB-231 tumor growth and metastasis, in vivo.

3.3. SH003 Inhibits Cell Proliferation and Induces Apoptosis. To examine anticancer effects of $\mathrm{SH} 003$ on different types of breast cancer cells, MCF-7, T47D, SKBR-3, BT-20, MDAMB-231, and GBL-60 cells were treated with different doses of each component of SH003 for 72 hours. While all herbal extracts we tested affected viabilities on different breast 


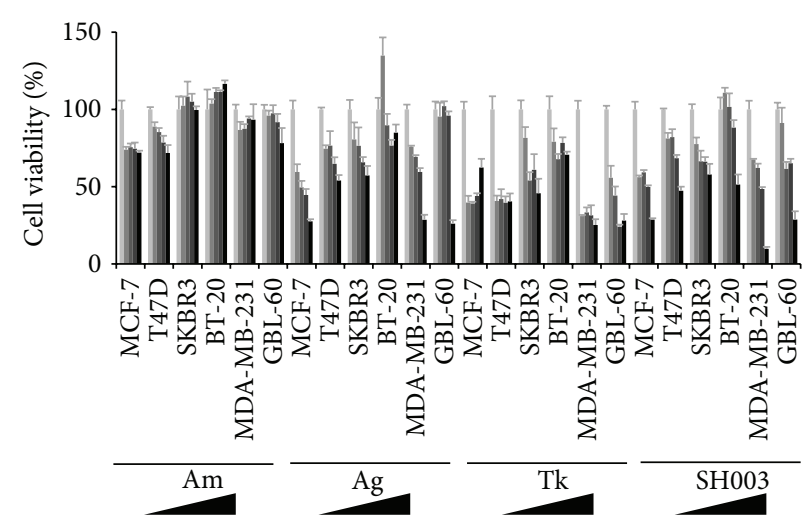

(a)

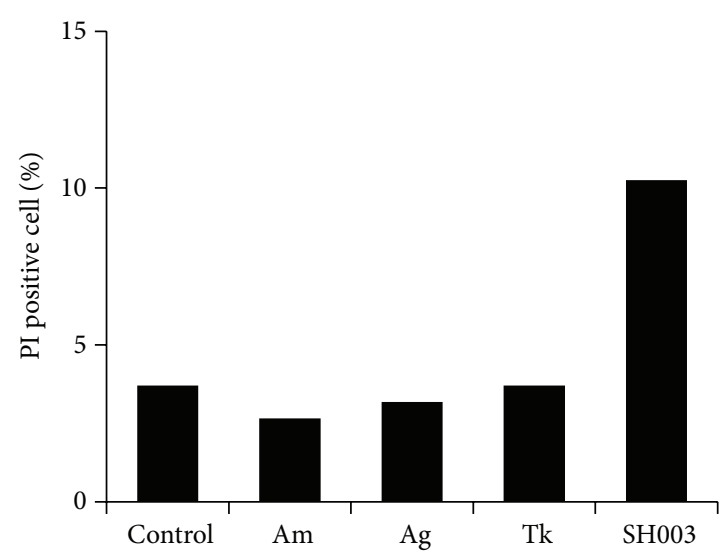

(b)

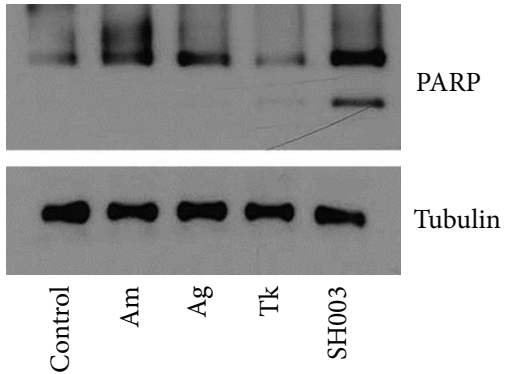

(c)

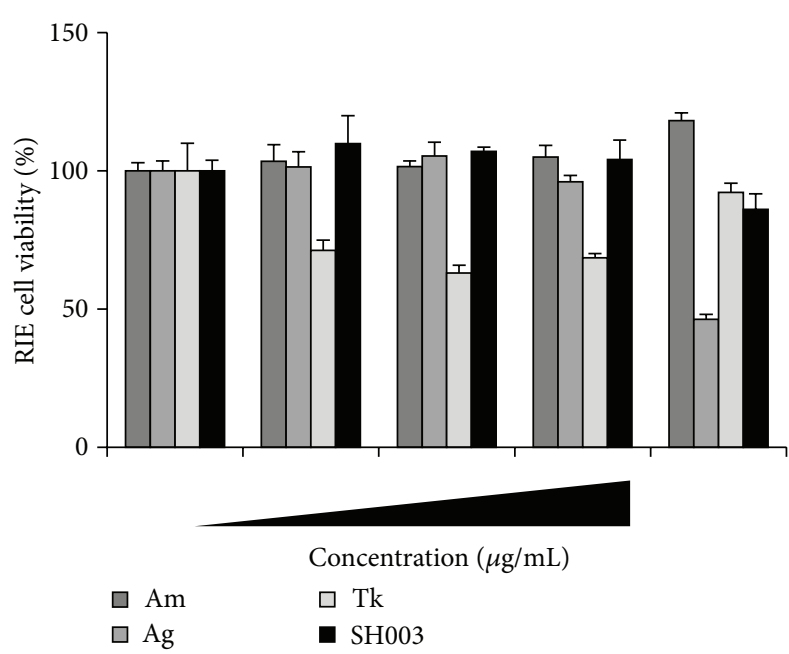

(d)

FIGURE 3: SH003 inhibits MDA-MB-231 growth and induces apoptosis. (a) Different breast cancer cells were seeded on 96-well plates and treated with each extract at different concentrations for 72 hours. Experiments were performed three times in sextuplicate. Representative data were presented as the means and standard deviations. Right triangles indicate the doses of each extract $(0,50,100,200$, and $500 \mu \mathrm{g} / \mathrm{mL})$, which was also marked with bars in different colors. (b) MDA-MB-231 cells were treated with $500 \mu \mathrm{g} / \mathrm{mL}$ of the each extract. Cells were stained with propidium iodide (PI, $50 \mu \mathrm{g} / \mathrm{mL}$ ) at room temperature in the dark. PI-positive apoptotic cells were detected using FACSCalibur. ${ }^{*} P<0.05$. (c) MDA-MB-231 cells were treated with the indicatives at $500 \mu \mathrm{g} / \mathrm{mL}$ for 24 hours and then subjected to western blots. Tubulin was used for the intimal control. (d) RIE cells were seeded on 96-well plates and treated with each extract at different concentrations for 72 hours. Experiments were performed three times in sextuplicate. Representative data were presented as the means and standard deviations.

cancer cell lines, SH003 much strongly inhibited MDA-MB231 cell viability at $500 \mu \mathrm{g} / \mathrm{mL}$. When MDA-MB-231 cells were treated with $\mathrm{SH} 003$ at $500 \mu \mathrm{g} / \mathrm{mL}$ for 72 hours, percentages of viable MDA-MB-231 cells were approximately $9.8 \%$ (Figure 3(a)). In addition, SH003 highly increased PI-positive apoptotic cell numbers (Figure 3(b)). Accordingly, SH003 caused PARP cleavages, whereas single components did not affect it (Figure 3(c)). In addition, SH003 did not affect normal rat intestinal epithelial cell viabilities, while an extract from either $\mathrm{Ag}$ or $\mathrm{Tk}$ reduced cell viability (Figure 3(d)). Those indicate that $\mathrm{SH} 003$ ameliorates adverse effects of each component of SH003. Thus, our data indicate that SH003 but not each component uniquely inhibits MDA-MB-231 cell proliferation via apoptosis without affecting normal cell viability.
3.4. SH003 Inhibits Cell Proliferation, Migration, Invasion, and Anchorage-Independent Growth. We next examined whether SH003 affects migratory abilities of MDA-MB-231 cells. $50 \mu \mathrm{g} / \mathrm{mL}$ of SH003 inhibited MDA-MB-231 cell migration by approximately $40 \%$ (Figure $4(\mathrm{a})$ ). When we examined an invasiveness of MDA-MB-231 cells, SH003 at $50 \mu \mathrm{g} / \mathrm{mL}$ inhibited cell invasion by $30 \%$ (Figure $4(\mathrm{~b})$ ). Next, in the soft agar assays, SH003 at $500 \mu \mathrm{g} / \mathrm{mL}$ inhibited anchorageindependent growth of MDA-MB-231 by 95\% (Figure 4(c)). Thus, our data indicate that $\mathrm{SH} 003$ inhibits in vitro metastatic abilities of MDA-MB-231 cells such as cell migration, invasion, and anchorage-independent growth. STAT3 Transcriptional Activation. To decipher anticancer 


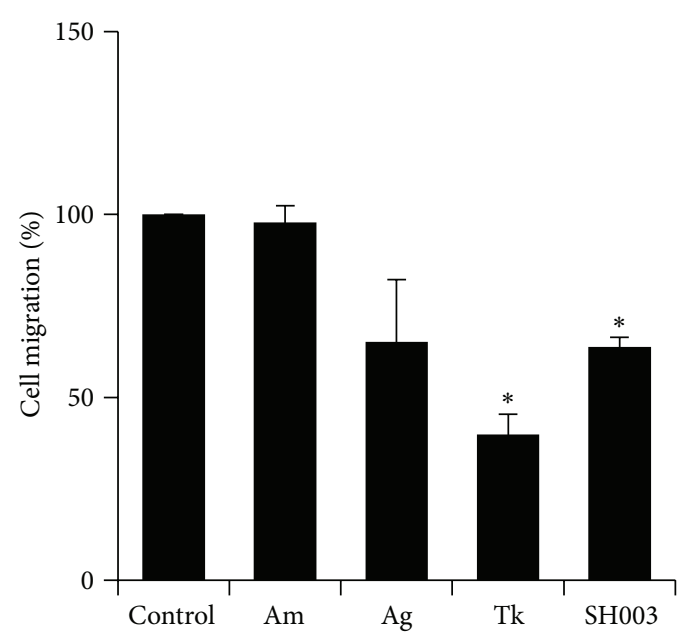

(a)

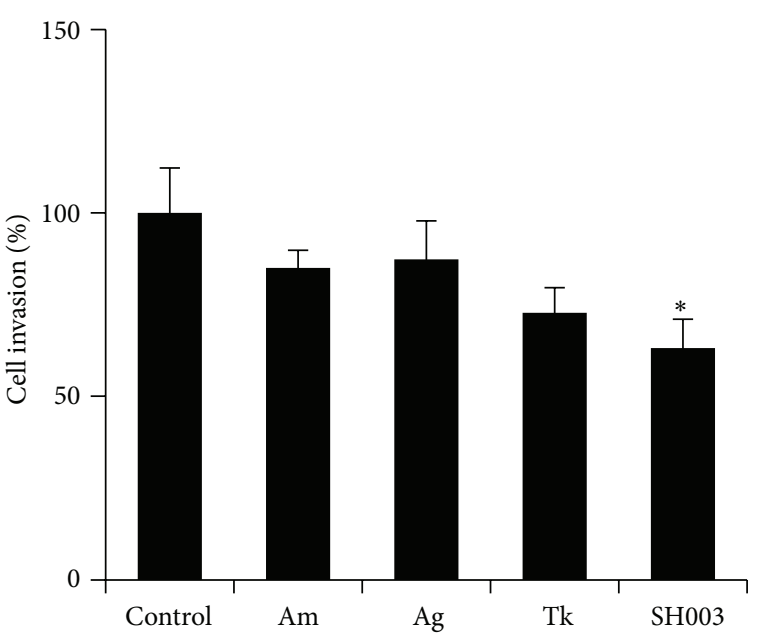

(b)

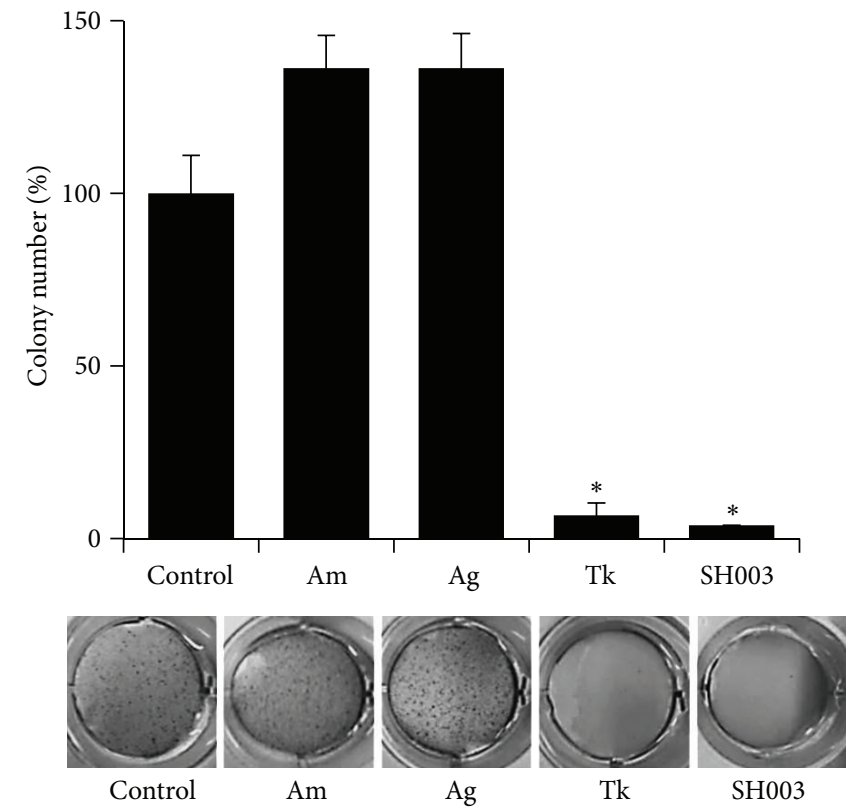

(c)

Figure 4: SH003 inhibits metastatic abilities in vitro. (a) MDA-MB-231 cells were scratched and treated with the indicatives for 24 hours. Cell migration was determined by counting cell numbers migrated from the wounding region. ${ }^{*} P<0.05$. (b) MDA-MB-231 cells were cultured on the upper chambers and treated with the indicatives for 24 hours. Invading cells were stained with crystal violet and then cell numbers were measured. ${ }^{*} P<0.05$. (c) MDA-MB-231 cells were cultured in soft agars and treated with the indicatives for 15 days. Colonies were then stained with crystal violet. ${ }^{*} P<0.05$.

effects of SH003 on MDA-MB-231 cells, we next examined intracellular signaling pathway. Cells were treated with each extract at $50 \mu \mathrm{g} / \mathrm{mL}$ (Figure 5(a)) or $500 \mu \mathrm{g} / \mathrm{mL}$ (Figure 5(b)) for 15 minutes and subjected to the western blots. While phosphorylation of EGFR and SRC was partly reduced by $50 \mu \mathrm{g} / \mathrm{mL}$ of SH003 or each component (Am, Ag, and Tk), STAT3 phosphorylation was strongly and selectively inhibited by SH003. Furthermore, STAT3 phosphorylation was also selectively inhibited by SH003 at $500 \mu \mathrm{g} / \mathrm{mL}$, while each component at $500 \mu \mathrm{g} / \mathrm{mL}$ did not repress it. Therefore, we assumed that SH003 selectively blocked STAT3 phosphorylation.
Next, we examined whether SH003 affects transcriptional activities of STAT3. When STAT3 nuclear translocation was examined, SH003 at $500 \mu \mathrm{g} / \mathrm{mL}$ blocked nuclear translocation of phosphorylated STAT3 (Figure 5(c)). In the luciferase assays, $\mathrm{SH} 003$ at $500 \mu \mathrm{g} / \mathrm{mL}$ also inhibited transcriptional activities of STAT3 in constitutively active STAT3- (CASTAT3-) overexpressed 293T cells, while STAT3 silencing (STAT3i) in 293T cells reduced STAT3-dependent transcriptional activities (Figure 5(d), left). Likewise, SH003 reduced STAT3 transcriptional activities in MDA-MB-231 cells where STAT3 is constitutively activated, which was similar to the effect of STAT3 silencing on STAT3 transcriptional activity 


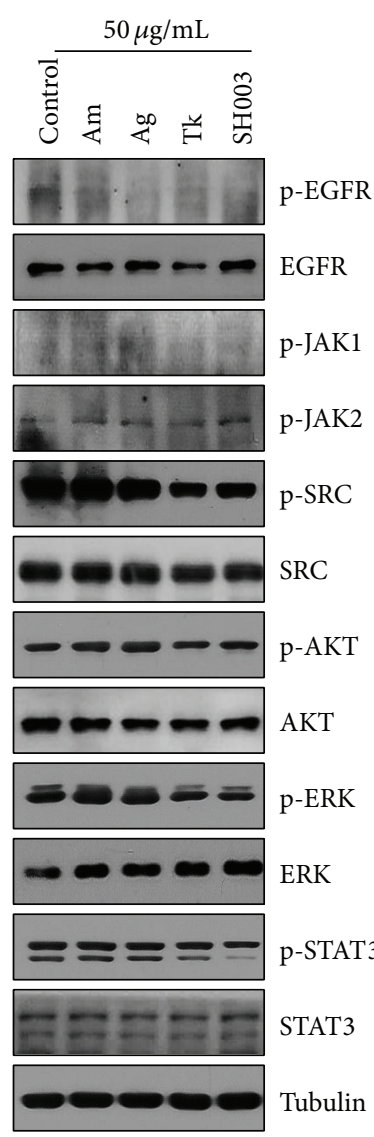

(a)

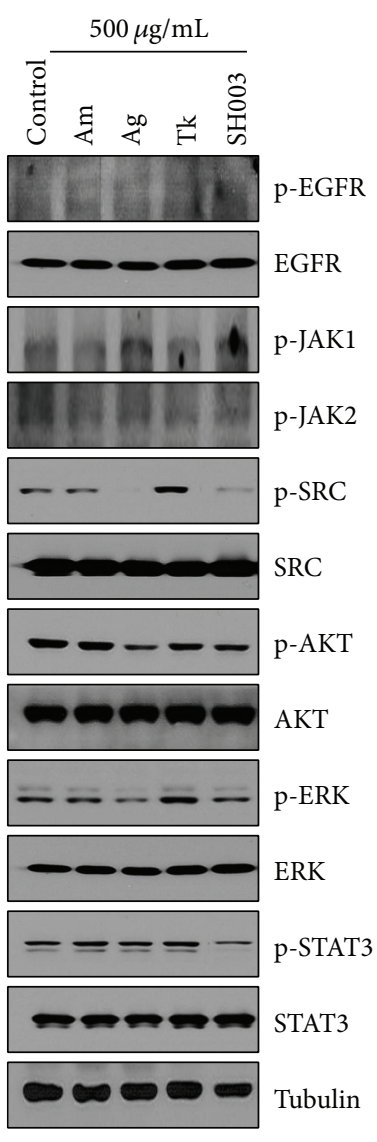

(b)

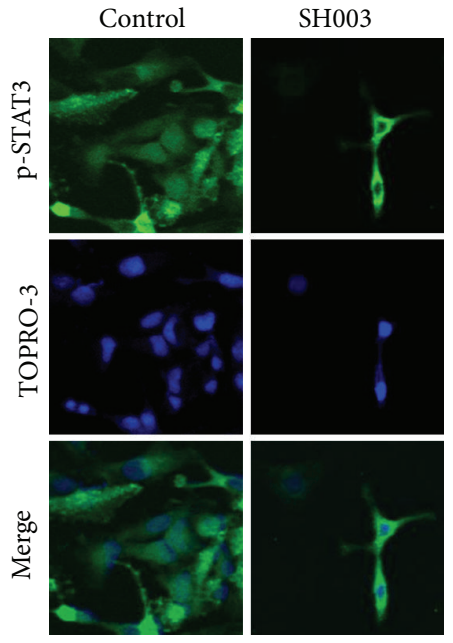

(c)
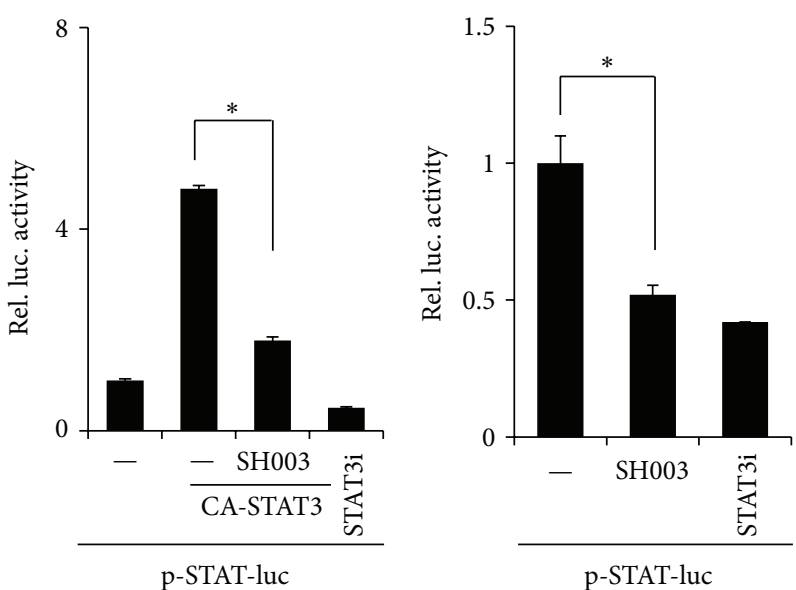

(d)

FIGURE 5: SH003 selectively inhibits STAT3 phosphorylation and transcriptional activity. ((a) and (b)) MDA-MB-231 cells were treated with the indicatives at 50 or $500 \mu \mathrm{g} / \mathrm{mL}$ for 15 minutes and then subjected to western blots with the antibodies indicated. Tubulin was used for the internal control. (c) Cells were treated with the indicatives for 6 hours and then stained with anti-p-STAT3 antibody (green) and TOPRO-3 (blue). 20x objectives. A scale bar indicates $10 \mu \mathrm{m}$. (d) Representative data for the luciferase assays. 293T (left) and MDA-MB-231 (right) cells were transfected with the indicatives and then treated with each extract for 24 hours. Experiments were performed in triplicate. Bars indicate means and standard deviations. ${ }^{*} P<0.05$.

(Figure 5(d), right). Therefore, our data indicate that SH003 selectively inhibits STAT3 activity.

3.6. SH003 Inhibits Expression of STAT3 Target Genes and IL-6 Production. As SH003 suppressed STAT3 activation, we next examined whether SH003 affects expression patterns of STAT3-dependent genes. SH003 at $500 \mu \mathrm{g} / \mathrm{mL}$ inhibited protein expression levels of STAT3-dependent genes such as Cyclin D, MMP-9, VEGF, and Survivin, while $50 \mu \mathrm{g} / \mathrm{mL}$ of SH003 only decreased levels of Cyclin D1 and MMP-9 


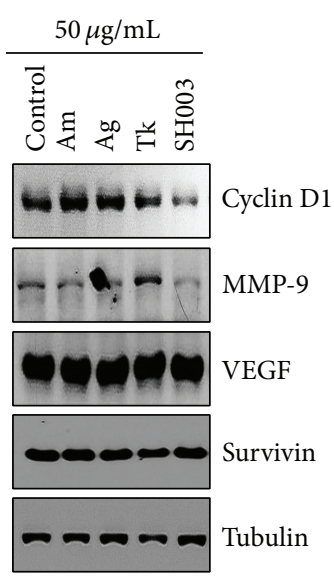

(a)

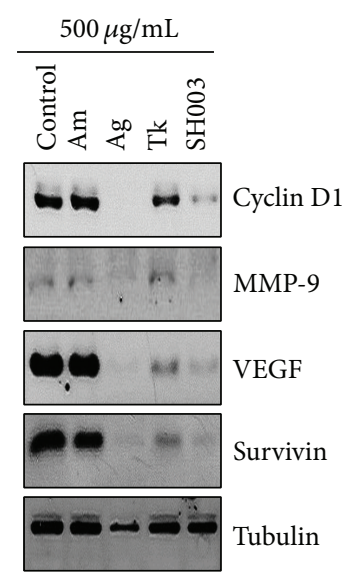

(b)

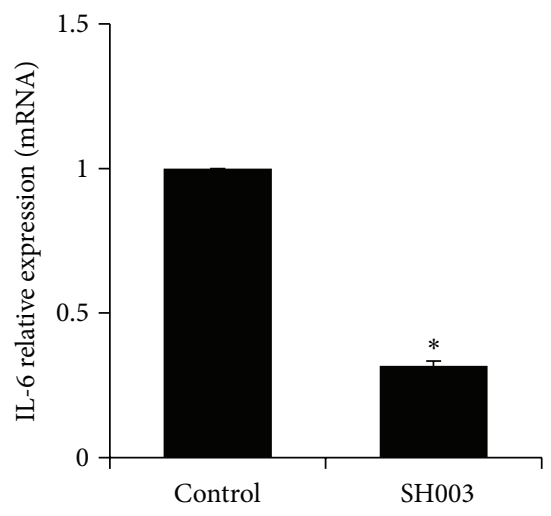

(c)

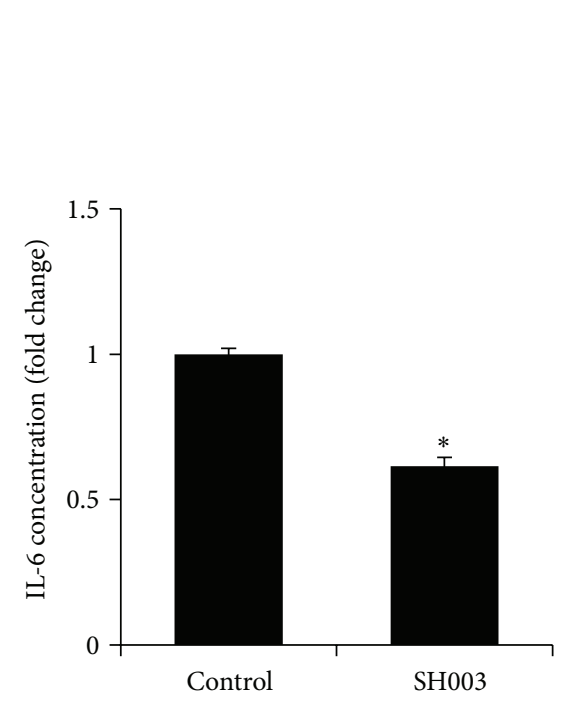

(d)

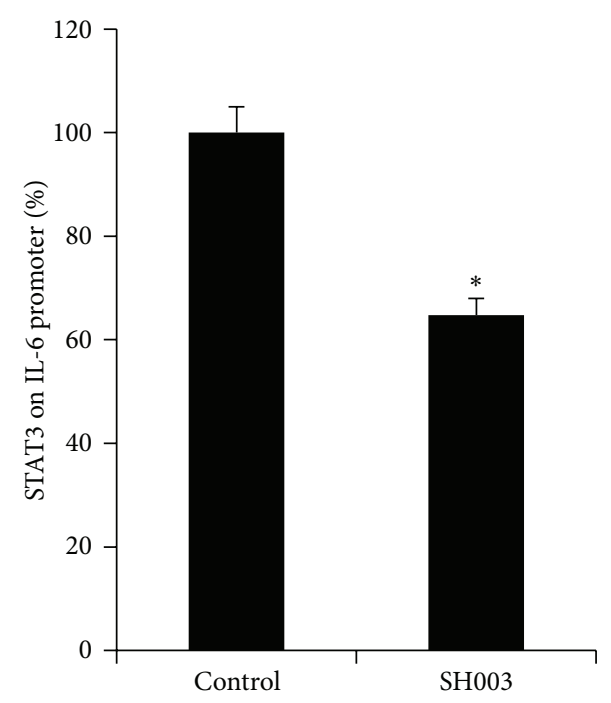

(e)

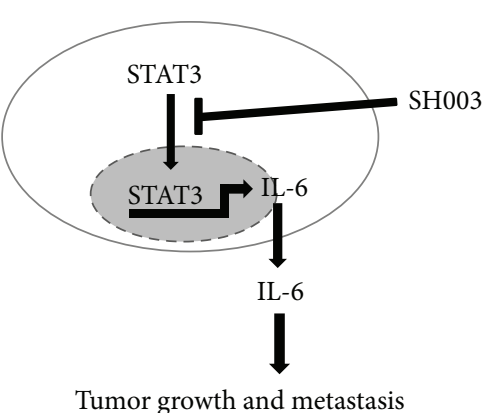

(f)

FiguRE 6: SH003 inhibits STAT3 target gene expression. ((a) and (b)) MDA-MB-231 cells were treated with the indicatives at 50 or $500 \mu \mathrm{g} / \mathrm{mL}$ for 24 hours and then subjected to western blots with the antibodies indicated. Tubulin was detected as a loading control. (c) MDA-MB-231 cells were treated with the indicatives at $500 \mu \mathrm{g} / \mathrm{mL}$ for 24 hours and then subjected to real-time PCR for IL-6 mRNA expression levels. Experiments were performed in triplicate. Bars indicate means and standard deviations. ${ }^{*} P<0.05$. (d) MDA-MB-231 cells were treated with the indicatives at $500 \mu \mathrm{g} / \mathrm{mL}$ for 24 hours and then harvested culture media. IL-6 levels were analyzed with ELISA assay. Experiments were performed in triplicate. Bars indicate means and standard deviations. ${ }^{*} P<0.05$. (e) Cells were treated with SH003 for 6 hours and then subjected to chromatin immunoprecipitation assays to test STAT3 interaction with IL-6 promoter. (f) A schematic model for anti-TNBC roles of SH003. TNBC has highly metastatic characteristics with constitutively active STAT3. SH003 selectively targets STAT3-dependent IL-6 production, resulting in the inhibition of TNBC growth and metastasis.

(Figures 6(c) and 6(d)). Those data indicated that expression patterns of those genes might be restricted by STAT3 transcriptional activity and that SH003 effect on those genes was not selective. As shown in Figure 6(c), we found that SH003 at $50 \mu \mathrm{g} / \mathrm{mL}$ or $500 \mu \mathrm{g} / \mathrm{mL}$ decreased IL-6 mRNA level by approximately $65 \%$ and $68 \%$, respectively. Next, when MDA-MB-231 cells were treated with SH003 at $50 \mu \mathrm{g} / \mathrm{mL}$ or $500 \mu \mathrm{g} / \mathrm{mL}$, their cultured media were subjected to ELISA assays. SH003 significantly inhibited secreted IL-6 level by approximately $33.5 \%$ and $38.6 \%$, respectively (Figure $6(\mathrm{~d})$ ). To confirm if SH003 inhibits STAT3 transcriptional activity for IL-6 expression, we performed chromatin immunoprecipitation assays. When MDA-MB-231 cells were treated with
SH003 at $50 \mu \mathrm{g} / \mathrm{mL}$ or $500 \mu \mathrm{g} / \mathrm{mL}$ for 6 hours, SH003 significantly blocked STAT3 interaction with IL-6 promoter region (Figure 6(e)). Thus, our data suggest that SH003 selectively inhibits STAT3-dependent IL-6 expression (Figure 6(f)).

\section{Discussion}

TNBC is highly metastasizing with a severe recurrence rate, causing a death of patients [1-3,36-38]. Nevertheless, TNBC is yet clearly curable. Traditional herbal medicines are revisited in cancer biology because those have less adverse effects but better anticancer effects $[4,5]$. In this study, we found 
that SH003 strongly suppressed tumor growth and metastasis of MDA-MB-231 cells defined as TNBC by inhibiting STAT3 activity. Thus, our new herbal extract SH003 appears to be useful for TNBC treatment.

$\mathrm{SH} 003$ is extracted from the mixture of Am, Ag, and Tk. Our in vitro studies demonstrate that the extract from either Ag or Tk is highly toxic in normal intestinal epithelial cells, while our data and previous reports have shown that the extract from Am, Ag, or Tk inhibited cancer cell growth [7, 10-13]. However, SH003 ameliorated this adverse effect and effectively inhibited tumor growth and metastatic abilities of MDA-MB-231, highly metastatic TNBC cell line, in vitro. Furthermore, SH003 suppressed in vivo MDA-MB-231 growth and metastasis with no effect on body weights. Thus, SH003 is safe and effective, both in vivo and in vitro.

STAT3 is crucial for cancer development and metastasis as well as cancer inflammation [39-43] and frequently activated in different types of cancers such as breast, lung, renal, prostate, pancreatic, colon, gastric, cervical, and ovarian cancers [44-47]. SH003 inhibited STAT3 transcriptional activity, while each component did not affect it. Interestingly, $50 \mu \mathrm{g} / \mathrm{mL}$ of SH003 reduced expression levels of MMP-9 and Cyclin D1 with no alterations of Survivin and VEGF, whereas $500 \mu \mathrm{g} / \mathrm{mL}$ of SH003 reduced all we tested. Furthermore, each component also reduced protein expression of those genes. As SH003 uniquely inhibited STAT3-dependent IL6 expression, our data suggest that $\mathrm{SH} 003$ may selectively target STAT3-IL-6 pathway. Meanwhile, we could not exclude a possibility that $\mathrm{SH} 003$ is likely to target other molecules beyond STAT3 to suppress MDA-MB-231 cell growth and metastatic abilities. In addition, it remains to be defined how SH003 has this selective effect.

\section{Conclusions}

In conclusion, we provide evidence that anticancer effect of SH003 on MDA-MB-231 cells results from the inhibition of STAT3-dependent IL-6 production. As STAT3 is mutated in different cancer types, it is worth testing if $\mathrm{SH} 003$ is able to target those types of cancer cells.

\section{Conflict of Interests}

The authors declare that they hold a patent.

\section{Authors' Contribution}

Youn Kyung Choi, Sung-Gook Cho, and Sang-Mi Woo equally contributed to this work.

\section{Acknowledgments}

The authors thank Hanpoong Pharmaceutics (Jeonju, Republic of Korea) for providing and analyzing herbal extracts, Dr. Sang Hoon Kim (Department of Biology, Kyung Hee University) for sharing the luminometer, and Dr. Sun Ha Paek (Seoul National University Hospital) for providing GBL-60 cell line. This research was supported by a grant from Korean Medicine R\&D Project of the Ministry of Health and Welfare (B110043 and B120014) and by a grant from Basic Science Research Program through the National Research Foundation of Korea (NRF) funded by the Ministry of Education, Science and Technology (2011-0022382). This work is under patent application.

\section{References}

[1] L. Schwentner, R. Wolters, K. Koretz et al., "Triple-negative breast cancer: the impact of guideline-adherent adjuvant treatment on survival-a retrospective multi-centre cohort study," Breast Cancer Research and Treatment, vol. 132, no. 3, pp. 10731080, 2012.

[2] J. Li, A. M. Gonzalez-Angulo, P. K. Allen et al., “Triple-negative subtype predicts poor overall survival and high locoregional relapse in inflammatory breast cancer," Oncologist, vol. 16, no. 12, pp. 1675-1683, 2011.

[3] R. Dent, M. Trudeau, K. I. Pritchard et al., "Triple-negative breast cancer: clinical features and patterns of recurrence," Clinical Cancer Research, vol. 13, no. 15, pp. 4429-4434, 2007.

[4] S. Wang, X. Wu, M. Tan et al., "Fighting fire with fire: poisonous Chinese herbal medicine for cancer therapy," Journal of Ethnopharmacology, vol. 140, no. 1, pp. 33-45, 2012.

[5] F. H. Qi, A. Li, Y. Inagaki et al., "Chinese herbal medicines as adjuvant treatment during chemoor radio-therapy for cancer," BioScience Trends, vol. 4, no. 6, pp. 297-307, 2010.

[6] H. M. Cheng, C. C. Li, C. Y. C. Chen et al., "Application of bioactivity database of Chinese herbal medicine on the therapeutic prediction, drug development, and safety evaluation," Journal of Ethnopharmacology, vol. 132, no. 2, pp. 429-437, 2010.

[7] J. W. Shin, J. Y. Son, J. K. Kang, S. H. Han, C. K. Cho, and C. G. Son, "Trichosanthes kirilowii tuber extract induces G2/M phase arrest via inhibition of tubulin polymerization in HepG2 cells," Journal of Ethnopharmacology, vol. 115, no. 2, pp. 209-216, 2008.

[8] S. Kongtun, W. Jiratchariyakul, T. Kummalue, P. Tan-ariya, S. Kunnachak, and A. W. Frahm, "Cytotoxic properties of root extract and fruit juice of Trichosanthes cucumerina," Planta Medica, vol. 75, no. 8, pp. 839-842, 2009.

[9] B. G. Heo, S. U. Chon, Y. J. Park et al., "Antiproliferative activity of Korean wild vegetables on different human tumor cell lines," Plant Foods for Human Nutrition, vol. 64, no. 4, pp. 257-263, 2009.

[10] L. K. Li, W. J. Kuang, Y. F. Huang et al., "Anti-tumor effects of Astragalus on hepatocellular carcinoma in vivo," Indian Journal of Pharmacology, vol. 44, no. 1, pp. 78-81, 2012.

[11] W. C. S. Cho and K. N. Leung, "In vitro and in vivo anti-tumor effects of Astragalus membranaceus," Cancer Letters, vol. 252, no. 1, pp. 43-54, 2007.

[12] X. D. Cheng, C. H. Hou, X. J. Zhang et al., "Effects of Huangqi (Hex) on inducing cell differentiation and cell death in K562 and HEL cells," Acta Biochimica et Biophysica Sinica, vol. 36, no. 3, pp. 211-217, 2004.

[13] R. Cui, J. He, B. Wang et al., "Suppressive effect of Astragalus membranaceus Bunge on chemical hepatocarcinogenesis in rats," Cancer Chemotherapy and Pharmacology, vol. 51, no. 1, pp. 75-80, 2003.

[14] J. Lv, Z. Zhao, Y. Chen et al., "The Chinese herbal decoction Danggui Buxue Tang inhibits angiogenesis in a rat model of 
liver fibrosis," Evidence-Based Complementary and Alternative Medicine, vol. 2012, Article ID 284963, 11 pages, 2012.

[15] W. L. Zhang, K. Y. Z. Zheng, K. Y. Zhu et al., "Chemical and biological assessment of Angelica herbal decoction: comparison of different preparations during historical applications," Phytomedicine, vol. 19, no. 11, pp. 1042-1048, 2012.

[16] M. Yang, G. C. F. Chan, R. Deng et al., "An herbal decoction of Radix astragali and Radix angelicae sinensis promotes hematopoiesis and thrombopoiesis," Journal of Ethnopharmacology, vol. 124, no. 1, pp. 87-97, 2009.

[17] C. A. Martey, S. J. Pollock, C. K. Turner et al., "Cigarette smoke induces cyclooxygenase-2 and microsomal prostaglandin E2 synthase in human lung fibroblasts: implications for lung inflammation and cancer," American Journal of Physiology: Lung Cellular and Molecular Physiology, vol. 287, no. 5, pp. L981-L991, 2004.

[18] R. M. Peek Jr. and J. E. Crabtree, "Helicobacter infection and gastric neoplasia," Journal of Pathology, vol. 208, no. 2, pp. 233248, 2006.

[19] P. E. Castle, S. L. Hillier, L. K. Rabe et al., "An association of cervical inflammation with high-grade cervical neoplasia in women infected with oncogenic human papillomavirus (HPV)," Cancer Epidemiology Biomarkers and Prevention, vol. 10, no. 10, pp. 1021-1027, 2001.

[20] G. Garcea, A. R. Dennison, W. P. Steward, and D. P. Berry, "Role of inflammation in pancreatic carcinogenesis and the implications for future therapy," Pancreatology, vol. 5, no. 6, pp. 514-529, 2005.

[21] P. A. Vagefi and W. E. Longo, "Colorectal cancer in patients with inflammatory bowel disease," Clinical Colorectal Cancer, vol. 4, no. 5, pp. 313-319, 2005.

[22] W. G. Nelson, A. M. de Marzo, T. L. DeWeese, and W. B. Isaacs, "The role of inflammation in the pathogenesis of prostate cancer," Journal of Urology, vol. 172, no. 5, part 2, pp. S6-12.

[23] A. Mantovani, "Cancer: inflammation by remote control," Nature, vol. 435, no. 7043, pp. 752-753, 2005.

[24] L. M. Coussens and Z. Werb, "Inflammation and cancer," Nature, vol. 420, no. 6917, pp. 860-867, 2002.

[25] A. Mantovani, P. Allavena, A. Sica, and F. Balkwill, "Cancerrelated inflammation," Nature, vol. 454, no. 7203, pp. 436-444, 2008.

[26] R. Salgado, S. Junius, I. Benoy et al., "Circulating interleukin-6 predicts survival in patients with metastatic breast cancer," International Journal of Cancer, vol. 103, no. 5, pp. 642-646, 2003.

[27] C. Huang, G. Yang, T. Jiang, K. Huang, J. Cao, and Z. Qiu, "Effects of IL-6 and AG490 on regulation of Stat3 signaling pathway and invasion of human pancreatic cancer cells in vitro," Journal of Experimental \& Clinical Cancer Research, vol. 29, article 51, 2010.

[28] N. Adam, B. Rabe, J. Suthaus, J. Grötzinger, S. Rose-John, and J. Scheller, "Unraveling viral interleukin-6 binding to gp130 and activation of STAT-signaling pathways independently of the interleukin-6 receptor," Journal of Virology, vol. 83, no. 10, pp. 5117-5126, 2009.

[29] H. Lee, P. Zhang, A. Herrmann et al., "Acetylated STAT3 is crucial for methylation of tumor-suppressor gene promoters and inhibition by resveratrol results in demethylation," Proceedings of the National Academy of Sciences of the United States of America, vol. 109, no. 20, pp. 7765-7769, 2012.
[30] X. S. Deng, S. Wang, A. Deng et al., "Metformin targets Stat3 to inhibit cell growth and induce apoptosis in triple-negative breast cancers," Cell Cycle, vol. 11, no. 2, pp. 367-376, 2012.

[31] Y. K. Choi, S. M. Woo, S. G. Cho et al., "Brain-metastatic triplenegative breast cancer cells regain growth ability by altering gene expression patterns," Cancer Genomics Proteomics, vol. 10, no. 6, pp. 265-275.

[32] D. Besser, J. F. Bromberg, J. E. Darnell Jr., and H. Hanafusa, "A single amino acid substitution in the v-Eyk intracellular domain results in activation of Stat 3 and enhances cellular transformation," Molecular and Cellular Biology, vol. 19, no. 2, pp. 1401-1409, 1999.

[33] J. Hillion, S. Dhara, T. F. Sumter et al., "The high-mobility group Ala/signal transducer and activator of transcription-3 axis: an achilles heel for hematopoietic malignancies?" Cancer Research, vol. 68, no. 24, pp. 10121-10127, 2008.

[34] S. Huang and F. A. Sinicrope, "Sorafenib inhibits STAT3 activation to enhance TRAIL-mediated apoptosis in human pancreatic cancer cells," Molecular Cancer Therapeutics, vol. 9, no. 3, pp. 742-750, 2010.

[35] A. Hoeben, B. Landuyt, M. S. Highley, H. Wildiers, A. T. van Oosterom, and E. A. de Bruijn, "Vascular endothelial growth factor and angiogenesis," Pharmacological Reviews, vol. 56, no. 4, pp. 549-580, 2004.

[36] R. Siegel, C. DeSantis, K. Virgo et al., "Cancer treatment and survivorship statistics, 2012," CA: A Cancer Journal for Clinicians, vol. 62, no. 4 , pp. 220-241.

[37] Cancer Genome Atlas Network, "Comprehensive molecular portraits of human breast tumours," Nature, vol. 490, no. 7418, pp. 61-70.

[38] A. Berghoff, Z. Bago-Horvath, C. de Vries et al., "Brain metastases free survival differs between breast cancer subtypes," The British Journal of Cancer, vol. 106, no. 3, pp. 440-446, 2012.

[39] F. Ripamonti, L. Albano, A. Rossini et al., "EGFR through STAT3 modulates $\triangle \mathrm{N} 63 \alpha$ expression to sustain tumor-initiating cell proliferation in squamous cell carcinomas," Journal of Cellular Physiology, vol. 228, no. 4, pp. 871-878, 2013.

[40] L. Malorni, P. B. Shetty, C. de Angelis et al., "Clinical and biologic features of triple-negative breast cancers in a large cohort of patients with long-term follow-up," Breast Cancer Research and Treatment, vol. 136, no. 3, pp. 795-804, 2012.

[41] W. Zhou, J. R. Grandis, and A. Wells, "STAT3 is required but not sufficient for EGF receptor-mediated migration and invasion of human prostate carcinoma cell lines," British Journal of Cancer, vol. 95, no. 2, pp. 164-171, 2006.

[42] G. Berclaz, H. J. Altermatt, V. Rohrbach, A. Siragusa, E. Dreher, and P. D. Smith, "EGFR dependent expression of STAT3 (but not STAT1) in breast cancer," International Journal of Oncology, vol. 19, no. 6, pp. 1155-1160, 2001.

[43] S. Grivennikov, E. Karin, J. Terzic et al., "IL-6 and Stat3 are required for survival of intestinal epithelial cells and development of colitis-associated cancer," Cancer Cell, vol. 15, no. 2, pp. 103-113, 2009.

[44] D. R. Hodge, E. M. Hurt, and W. L. Farrar, "The role of IL-6 and STAT3 in inflammation and cancer," European Journal of Cancer, vol. 41, no. 16, pp. 2502-2512, 2005.

[45] H. Yu, D. Pardoll, and R. Jove, "STATs in cancer inflammation and immunity: a leading role for STAT3," Nature Reviews Cancer, vol. 9, no. 11, pp. 798-809, 2009. 
[46] S. Huang, "Regulation of metastases by signal transducer and activator of transcription 3 signaling pathway: clinical implications," Clinical Cancer Research, vol. 13, no. 5, pp. 1362-1366, 2007.

[47] M. Z. Kamran, P. Patil, and R. P. Gude, "Role of STAT3 in cancer metastasis and translational advances," BioMed Research International, vol. 2013, Article ID 421821, 15 pages, 2013. 


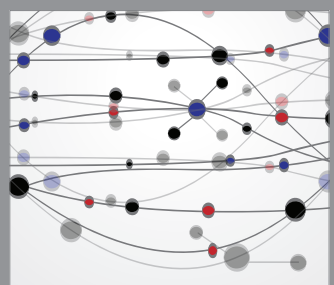

The Scientific World Journal
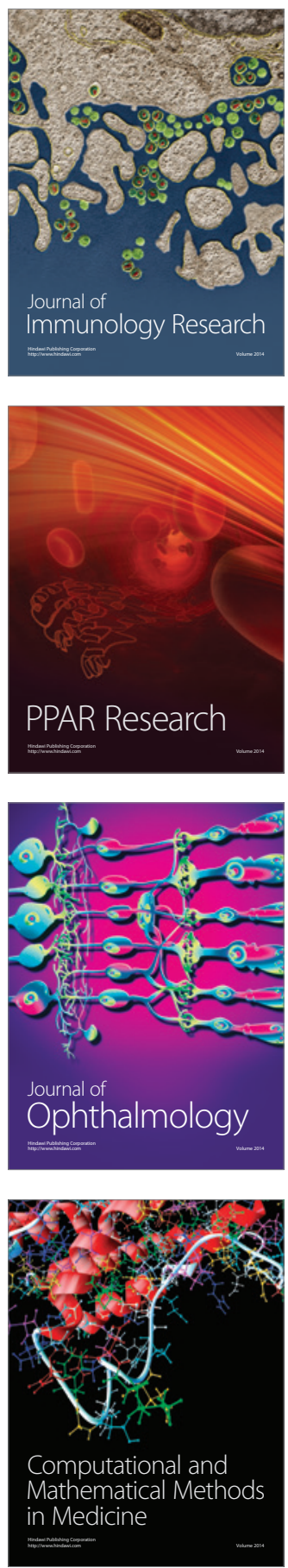

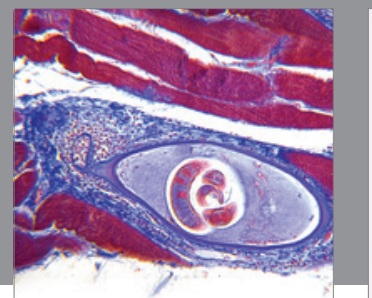

Gastroenterology

Research and Practice
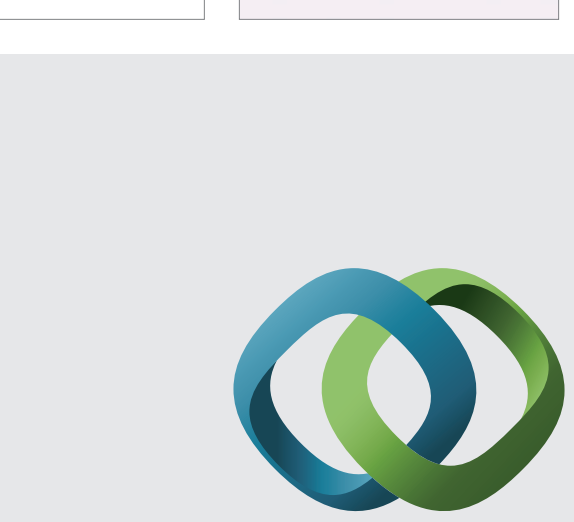

\section{Hindawi}

Submit your manuscripts at

http://www.hindawi.com
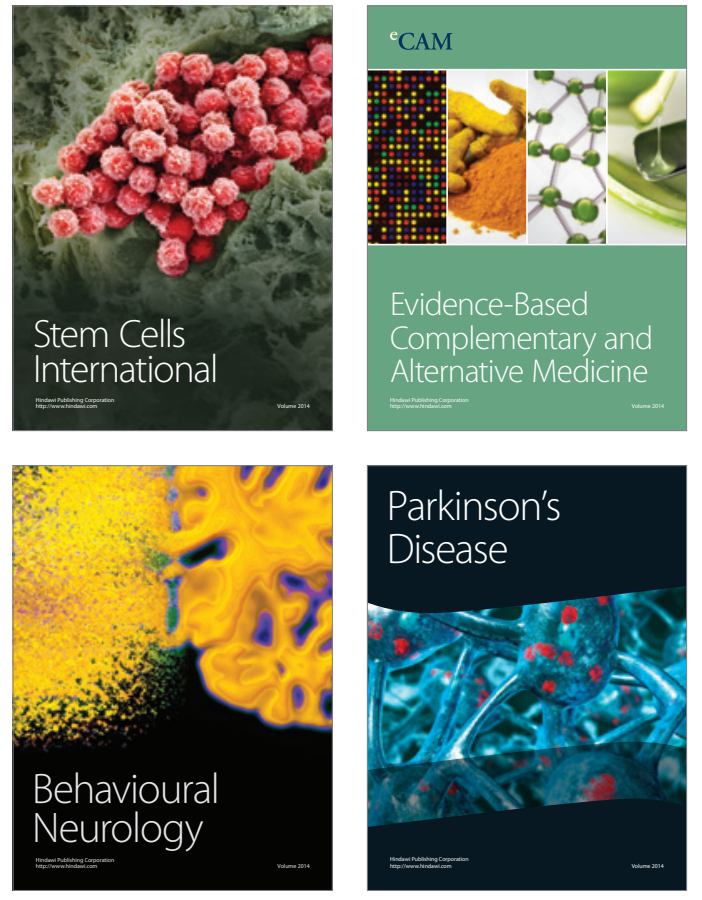
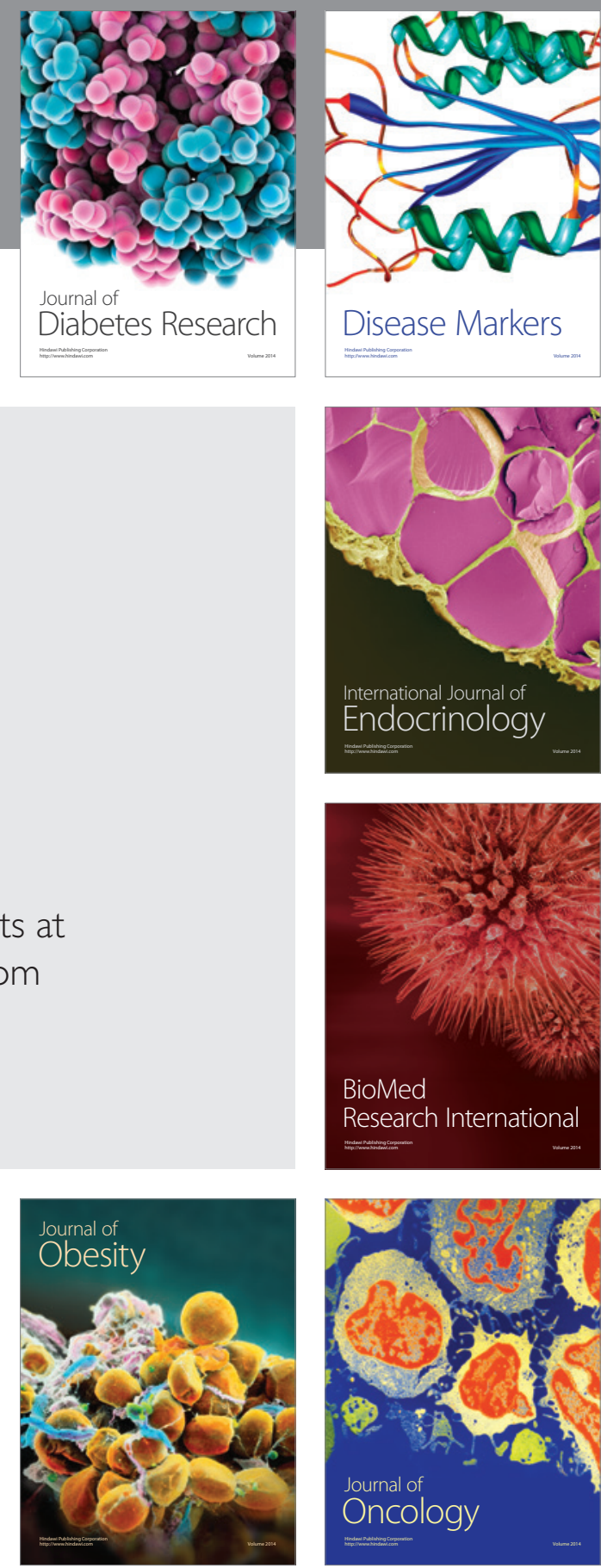

Disease Markers
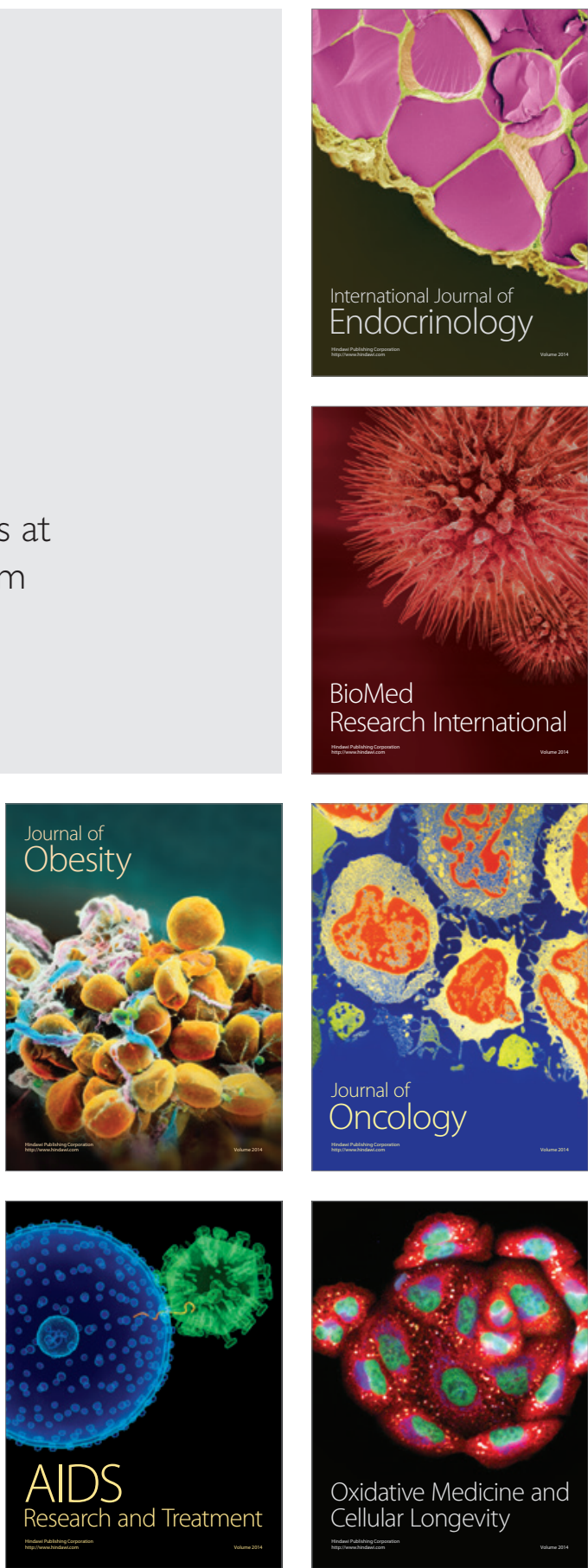